OPEN ACCESS

Edited by: Sebastian Fraune, University of Kiel, Germany

Reviewed by:

Michael Sweet,

University of Derby, United Kingdom

Josefa Antón,

University of Alicante, Spain

*Correspondence:

Hannah E. Epstein

hannah.epstein@my.jcu.edu.au

Specialty section:

This article was submitted to

Microbial Symbioses,

a section of the journal

Frontiers in Microbiology

Received: 18 March 2019

Accepted: 18 July 2019

Published: 16 August 2019

Citation:

Epstein HE, Smith HA, Cantin NE,

Mocellin VJL. Torda G and

van Oppen MJH (2019) Temporal

Variation in the Microbiome

of Acropora Coral Species Does Not

Reflect Seasonality.

Front. Microbiol. 10:1775

doi: 10.3389/fmicb.2019.01775

\section{Temporal Variation in the Microbiome of Acropora Coral Species Does Not Reflect Seasonality}

\author{
Hannah E. Epstein 1,2,3*, Hillary A. Smith ${ }^{4}$, Neal E. Cantin ${ }^{3}$, Veronique J. L. Mocellin ${ }^{3}$, \\ Gergely Torda ${ }^{1,3}$ and Madeleine J. H. van Oppen ${ }^{3,5}$
}

\begin{abstract}
'ARC Centre of Excellence for Coral Reef Studies, James Cook University, Townsville, QLD, Australia, ${ }^{2}$ AIMS@JCU, James Cook University, Townsville, QLD, Australia, ${ }^{3}$ Australian Institute of Marine Science, Townsville, QLD, Australia, ${ }^{4}$ College of Science and Engineering, James Cook University, Townsville, QLD, Australia, ${ }^{5}$ School of BioSciences, University of Melbourne, Parkville, VIC, Australia
\end{abstract}

The coral microbiome is known to fluctuate in response to environmental variation and has been suggested to vary seasonally. However, most studies to date, particularly studies on bacterial communities, have examined temporal variation over a time frame of less than 1 year, which is insufficient to establish if microbiome variations are indeed seasonal in nature. The present study focused on expanding our understanding of longterm variability in microbial community composition using two common coral species, Acropora hyacinthus, and Acropora spathulata, at two mid-shelf reefs on the Great Barrier Reef. By sampling over a 2-year time period, this study aimed to determine whether temporal variations reflect seasonal cycles. Community composition of both bacteria and Symbiodiniaceae was characterized through 16S rRNA gene and ITS2 rDNA metabarcoding. We observed significant variations in community composition of both bacteria and Symbiodiniaceae among time points for $A$. hyacinthus and A. spathulata. However, there was no evidence to suggest that temporal variations were cyclical in nature and represented seasonal variation. Clear evidence for differences in the microbial communities found between reefs suggests that reef location and coral species play a larger role than season in driving microbial community composition in corals. In order to identify the basis of temporal patterns in coral microbial community composition, future studies should employ longer time series of sampling at sufficient temporal resolution to identify the environmental correlates of microbiome variation.

Keywords: coral microbiome, temporal variation, season, bacteria, Symbiodiniaceae, GBR, metabarcoding

\section{INTRODUCTION}

Scleractinian corals are complex holobionts that host a high diversity and abundance of microbial symbionts that make up the coral microbiome (Blackall et al., 2015), some of which are essential to holobiont health, and function. Endosymbiotic microalgae of the family Symbiodiniaceae support coral growth and health by translocating carbon and other nutrients to the coral host (Lewis and Smith, 1971; Muscatine and Porter, 1977; Baker, 2001). Similarly, prokaryotes (i.e., bacteria and archaea) have been found to play a role in nutrient cycling, nitrogen fixation, and coral immunity (Rohwer and Kelley, 2004; Ritchie, 2006; Raina et al., 2009; Kimes et al., 2010; Bourne and Webster, 2013). 
The coral microbiome is rarely static and its members can fluctuate as a result of changes in environmental conditions, or possibly due to host regulatory mechanisms (reviewed in Bourne et al., 2016). Symbiodiniaceae communities may fluctuate according to season (e.g., Chen et al., 2005; Ulstrup et al., 2008), but can remain stable through time in some coral species (e.g., Thornhill et al., 2006a,b). Additionally, significant stress events, such as high temperatures resulting in bleaching, can cause these microalgal symbionts to undergo shuffling (e.g., Berkelmans and van Oppen, 2006) or trigger the acquisition of novel strains from the environment (i.e., "switching") (e.g., Boulotte et al., 2016). Further, the environment can modulate the initial uptake of Symbiodiniaceae, particularly in coral species that acquire these symbionts from the external environment during early development (LaJeunesse et al., 2004a). For prokaryote partners, variability in community composition is known to correlate with changing environmental conditions (reviewed in Thompson et al., 2015). Further, coral bacterial communities can vary geographically, where the same species can harbor vastly different communities of bacterial partners at different locations (e.g., Littman et al., 2009; Lee et al., 2012; HernandezAgreda et al., 2016). However, some bacterial members have been found consistently across all or most colonies of certain coral species, suggesting that there is a small number of stable members (i.e., the "coral microbial core"; Ainsworth et al., 2015; Hernandez-Agreda et al., 2017). Thus, it has been proposed that the coral bacterial community can be partitioned into a stable core component, a site-specific component, and a dynamic and variable component highly influenced by changes in abiotic and biotic factors (Hernandez-Agreda et al., 2016; Leite et al., 2018).

Recent advances in our understanding of the response of microbial community composition to environmental change have highlighted the potential role microbes play in coral host resilience. For instance, a stable microbiome has been suggested to confer host resilience when exposed to extreme conditions (O'Brien et al., 2018). Conversely, the microbiome has also been found to change and recover according to rapid environmental shifts (e.g., tides; Sweet et al., 2017 or acute pollution run-off events; Garren et al., 2009). Environmentally driven changes in the microbiome that result in increases or incorporation of better-adapted microbial taxa could theoretically aid or improve coral survival (e.g., Reshef et al., 2006; van Oppen et al., 2015, 2017; Peixoto et al., 2017; Torda et al., 2017). Understanding natural variability of the coral microbiome, particularly the potential for cyclical seasonal variation, can provide insight into how the microbiome may respond to environmental fluctuations and climate warming. Seasons present natural changes in factors such as temperature and irradiance (Warner et al., 2002; Bahr et al., 2017), dissolved calcium carbonate levels and aragonite saturation rate (Bates et al., 2010), and nutrient levels (particularly for coastal reefs influenced by run-off during rainy seasons; Costa et al., 2006). Long-term studies are available for Symbiodiniaceae communities, which have identified that some coral species exhibit seasonal variation in community composition (e.g., Chen et al., 2005; Ulstrup et al., 2008) while others remain stable through time (e.g., Thornhill et al., 2006a,b). Seasonal changes in Symbiodiniaceae may also manifest as changes to cell density, pigmentation or photo-efficiency (Fitt et al., 2000; Warner et al., 2002; Ulstrup et al., 2008). Variations in the coral bacterial community among time points have been suggested to reflect seasonal differences in their environment (e.g., Ceh et al., 2011; Kimes et al., 2013; Li et al., 2014; Sharp et al., 2017; Cai et al., 2018); however, all of these studies have lasted less than 1 year, which is insufficient to test hypotheses regarding seasonality. Indeed, one longer-term study (Yang et al., 2017) found the bacterial community of the brooding coral Stylophora pistillata to be dynamic, but not reflective of seasonal cycles (Yang et al., 2017).

The present study aimed to expand our understanding of long-term fluctuations in microbial community composition and examine whether temporal variations within the Symbiodiniaceae and bacterial members of the coral microbiome correlate with a seasonal cycle. To this aim, the community composition of bacteria and Symbiodiniaceae was characterized by DNA metabarcoding across a 2-year time period in two common species of coral on great barrier reef (GBR), Acropora hyacinthus and Acropora spathulata. Seasonality as well as the co-occurrences of microbial taxa through time were examined.

\section{MATERIALS AND METHODS}

\section{Sample Collection and Processing}

Twelve colonies each of two species of coral, A. hyacinthus and A. spathulata, at two mid-shelf reefs in the central GBR, Rib reef (18 29'4.8'S, $\left.146^{\circ} 52^{\prime} 13.7^{\prime \prime} \mathrm{E}\right)$, and Davies reef (18 49'23.8”S, $\left.147^{\circ} 38^{\prime} 56.2^{\prime \prime} \mathrm{E}\right)$, were tagged and sampled over a 2 -year time period. Both reef locations are similar distance from land, 75 and $79 \mathrm{~km}$ offshore, respectively. Sampling sites were back reef lagoon patch reef habitats and colonies were tagged at similar depths between 3-6 m. Sampling took place in February (end of summer) and October/November (end of winter) of both 2014 and 2015, as well as an additional time point in April 2015, making a total of five time points (Supplementary Table S1). At each time point and each location, a small nubbin of each colony was collected and immediately snap-frozen in liquid nitrogen $\left(\mathrm{LN}_{2}\right)$. Frozen samples were then freeze-dried and crushed using a hydraulic bench top laboratory press prior to DNA extraction. Average monthly temperature data over the duration of the study period from both Rib and Davies reef were obtained from publicly available data collected by the Australian Institute of Marine Science (AIMS Historical Data Tool ${ }^{1}$ ).

DNA was extracted using a traditional salting out method with an added lysozyme digestion and bead-beating step (Damjanovic et al., 2017). Amplification of double-stranded products from the 16S rRNA gene for bacteria and the internal transcribed spacer region 2 (ITS2) was achieved through polymerase chain reaction (PCR) using gene-specific primers. The V5-V6 region of $16 \mathrm{~S}$ was targeted using the primers 784F $5^{\prime}$ TCGTCGGCAGCGTCAGATGTGTATAAGAGACAGAGGATT AGATACCCTGGTA-3' and 1061R 5'-GTCTCGTGGGCTC

\footnotetext{
${ }^{1}$ http://data.aims.gov.au/aimsrtds/datatool.xhtml
} 
GGAGATGTGTATAAGAGACAGCRRCACGAGCTGACGAC3' (Andersson et al., 2008). ITS2 was targeted using the primers ITS2F $5^{\prime}$-TCGTCGGCAGCGTCAGATGTGTATAAG AGACAGGTGAATTGCAGAACTCCGTG-3' and ITS2R 5' GTCTCGTGGGCTCGGAGATGTGTATAAGAGACAGCCTCC GCTTACTTATATGCTT-3' (Pochon et al., 2012). Both sets of primers included the Illumina adapter overhangs for Illumina MiSeq sequencing, underlined in the above primer sequences.

The 16S PCR was carried out in triplicate $10 \mu \mathrm{L}$ reaction volumes, resulting in $30 \mu \mathrm{L}$ pooled PCR product. Each reaction consisted of: $5 \mu \mathrm{L}$ of AmpliTaq Gold MasterMix (Applied Biosystems), $2 \mu \mathrm{L}$ of each primer $(2 \mu \mathrm{M}$ stock), and $1 \mu \mathrm{L}$ of DNA template, with an additional no template control to test for contamination. All $16 \mathrm{~S}$ reactions were run on a Kyratec SC200 thermal cycler (Kyratec Life Science) using the following protocol: initial denaturation at $95^{\circ} \mathrm{C}$ for $10 \mathrm{~min}$, then 30 cycles of denaturation at $95^{\circ} \mathrm{C}$ for $30 \mathrm{~s}$, annealing at $57^{\circ} \mathrm{C}$ for $60 \mathrm{~s}$ and extension at $72^{\circ} \mathrm{C}$ for $60 \mathrm{~s}$, followed by a final extension at $72^{\circ} \mathrm{C}$ for $7 \mathrm{~min}$. The ITS2 PCR was also carried out in triplicate $10 \mu \mathrm{L}$ reactions. Each reaction consisted of $5 \mu \mathrm{L}$ of Qiagen Mulitplex MasterMix (Qiagen), $3 \mathrm{uL}$ Milli Q, $0.5 \mu \mathrm{L}$ of each primer (4 uM stock), and $1 \mu \mathrm{L}$ of DNA template. All ITS2 reactions were run on a Kyratec SC-200 thermal cycler (Kyratec Life Science) using the following protocol: $95^{\circ} \mathrm{C}$ for $5 \mathrm{~min}$, then 31 cycles of denaturation at $95^{\circ} \mathrm{C}$ for $30 \mathrm{~s}$, annealing at $55^{\circ} \mathrm{C}$ for $30 \mathrm{~s}$, and extension at $72^{\circ} \mathrm{C}$ for $30 \mathrm{~s}$, followed by a final extension at $72^{\circ} \mathrm{C}$ for $5 \mathrm{~min}$. All PCR products were then examined using gel electrophoresis on a $2 \%$ TBE-agarose gel stained with Ethidium Bromide (EtBr). Some ITS2 products displayed double-banding, representing both the target and a mitochondrial band. The target bands were poked using the tip of a clean pipette, introduced to clean PCR master mix, and underwent a second PCR with the same specifications but only 12 cycles of denaturation, annealing, and extension. These products were again checked by gel electrophoresis to ensure no double-banding prior to sequencing. PCR clean-up, indexing and sequencing were carried out at the Ramaciotti Centre for Genomics at the University of New South Wales on a 2 bp $\times 300$ bp Illumina MiSeq run. Data was returned as de-multiplexed paired-end sequences. Some coral samples had no amplification for either 16S or ITS2 and were thus left out of the downstream analyses (see Supplementary Table S2 for final sample sizes).

\section{Sequence Assembly, Quality Control, and Taxonomic Assignment}

Demultiplexed sequences for both 16S and ITS2 were assembled, checked for quality and assigned taxonomic classification using a QIIME2 v 2017.10 pipeline with additional plug-ins (Bolyen et al., 2018). The plug-in demux (Bolyen et al., 2018) was used for visualizing read quality and setting quality filtering guidelines. Quality filtering, trimming of poor-quality bases, dereplication, chimera filtering, merging paired-end reads, and the identification of amplicon sequence variants (ASVs) were performed using the DADA2 plug-in (Callahan et al., 2016). For $16 \mathrm{~S}$, mitochondrial and chloroplast sequences were removed and taxonomy was assigned by training a naïve-Bayes classifier on the
V5-V6 region of the 16S gene in the SILVA 128 database (Quast et al., 2013) using the feature-classifier plugin (Bolyen et al., 2018) to match the primers used. Due to the high number of singlevariants found for ITS2 and the subsequent small taxonomic database, it was not useful to use a classifier as above because the resolution was too low. Therefore, these single-variants for ITS2 were clustered by $97 \%$ similarity using a vsearch plug-in (Rognes et al., 2016). Taxonomic assignment was done according to the database from Arif et al. (2014). This allowed assignment down to the sub-type level for Symbiodiniaceae. At the end of the pipelines for both 16S and ITS2, the taxa plug-in (Bolyen et al., 2018) was used to create a feature table (biom table), and a taxonomy table with raw sequence counts that could then be used for further downstream analyses.

\section{Statistical Analyses}

Data were read into R v. 3.5.0 (R Core Team, 2018) and analyzed using the package phyloseq (McMurdie and Holmes, 2013). Contaminants and singletons were removed from the $16 S$ and ITS2 datasets prior to further analyses. Contaminants were identified using a similar method to that outlined in Lee et al. (2015); as contaminant taxa are expected to have high relative abundance in negatives and low relative abundance in samples, any ASV that exhibited a relative abundance of one or more orders of magnitude higher in negatives compared with coral samples were removed. Variations in alpha diversity (Shannon diversity index) and observed species richness of both bacteria and Symbiodiniaceae from the two coral species at both reefs and among time points were analyzed by analysis of variance (ANOVA) using a linear model fit by restricted maximum likelihood (REML) for repeated measures with an added autoregressive 1st order (AR1) correlation structure to account for time series autocorrelation in the $\mathrm{R}$ packages car (Fox and Weisberg, 2011) and nlme (Pinheiro et al., 2018). Post hoc comparisons were made using Tukey's test with the packages multcompView (Graves et al., 2015) and lsmeans (Lenth, 2016). Differences in beta-diversity among species, reefs, and time points were assessed using permutational multivariate analysis of variance (PERMANOVA) blocked by colony to account for repeated measures. Homogeneity of dispersions was assessed using PERMDISP. Both PERMANOVA and PERMDISP were run with 999 permutations and betadiversity was visualized using NMDS fit with environmental variables through constrained correspondence analysis (CCA) using the function envfit in vegan (Oksanen et al., 2018). Further exploration of microbial communities were examined through visualizing relative abundances with ggplot2 (Wickham, 2009), and bacterial indicator taxa (i.e., taxa that are identified as indicative of a specified treatment using both presence/absence and relative abundance) were characterized for each coral species at each reef among repeated time points (i.e., February and October/November) using a multi-level pattern analysis with 999 permutations in the package indicspecies (De Cáceres and Legendre, 2009). These indicators are used to identify consistencies between repeated time points.

Co-occurrences between bacteria and Symbiodiniaceae were determined using Spearman Rank correlation coefficients on 
ASVs appearing at least once in $20 \%$ or more of the samples using the packages corrplot (Wei and Simko, 2017) and igraph (Csardi and Nepusz, 2006) to optimize the number of microbial taxa included in the correlations. Correlation matrices of each species per reef were visualized in corrplot v. 0.84 (Wei and Simko, 2017). Significant correlations $(>0.6$ and $<-0.6, p<0.05)$ were identified and visualized as networks for each time point using Cytoscape v. 3.6.1 (Shannon et al., 2003).

\section{RESULTS}

\section{Temperature at Rib and Davies Reefs}

The average monthly temperatures for both Rib and Davies reefs exhibited a seasonal pattern and were similar through time (Figure 1). The February time points were situated at the maximum of the annual temperature cycle, however, February 2015 was approximately $0.5^{\circ} \mathrm{C}$ warmer than February 2014 (February 2014 data only available for Davies reef). October/November time points were situated at the end of the winter season, just after temperatures had begun to increase. In contrast to the summer timepoints, October/November 2015 was between 0.4 and $0.5^{\circ} \mathrm{C}$ cooler than October/November 2014 .

\section{Bacterial Community Characterization}

A total of 5,112,489 sequences from 216 samples corresponding to 14,083 unique ASVs were recovered to characterize the bacterial communities of $A$. hyacinthus and $A$. spathulata at the two mid-shelf reefs through time. Negative controls were checked for contamination and three ASVs from the genera Bradyrhizobium, Ralstonia, and Oxalobacteraceae were removed from the dataset.

Alpha diversity significantly varied through time for A. hyacinthus at Rib reef (ANOVA: $\mathrm{df}=4, F=7.39$, $p<0.001$ ) and for A. spathulata at Davies reef (ANOVA:

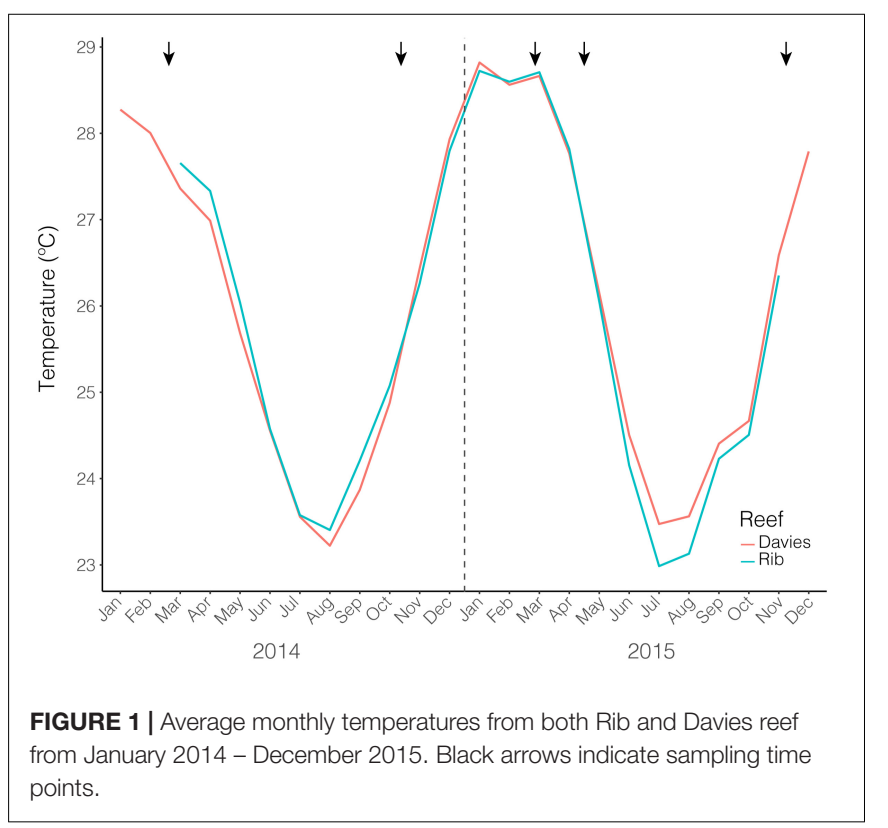

$\mathrm{df}=4, F=4.75, p<0.01)$. Alpha diversity did not significantly vary over time for $A$. hyacinthus at Davies reef or A. spathulata at Rib reef (Figure 2). Observed richness through time was also inconsistent across species and reefs. On average, A. hyacinthus had an average richness of $44.21 \pm 2.5$ and $48.7 \pm 2.9$ at Rib and Davies reefs, respectively, and $A$. spathulata had an average of $42.94 \pm 1.64$ and $40.44 \pm 1.63$ at Rib and Davies, respectively. Richness significantly varied through time for A. hyacinthus at Rib reef (ANOVA: $\mathrm{df}=4, F=2.69, p<0.05$ ) and for A. spathulata at both Rib (ANOVA: $\mathrm{df}=4, F=2.79, p<0.05$ ) and Davies reefs (ANOVA: $\mathrm{df}=4, F=3.13, p<0.05$ ), but not for A. hyacinthus at Davies reef.

Bacterial communities of all samples were dominated by the classes Gammaproteobacteria, Betaproteobacteria, Bacilli, Alphaproteobacteria, and Deltaproteobacteria (Figure 3 and Supplementary Figure S1). Gammaproteobacteria, which was dominated by the genus Endozoicomonas, made up a higher percentage of the community in samples taken from Rib reef, where it made up $90.2 \pm 2.2 \%$ and $70.3 \pm 2.9 \%$ (mean \pm SEM) for A. hyacinthus and A. spathulata, respectively. At Davies reef, Gammaproteobacteria accounted for $60 \pm 3.5 \%$ for A. hyacinthus and $45.4 \pm 3.9 \%$ for $A$. spathulata. An opposing pattern was observed for Betaproteobacteria; this class, which was dominated by the genus Burkholderia-Paraburkholderia, made up a higher percentage in samples taken at Davies reef as opposed to Rib reef. Betaproteobacteria at Davies reef accounted for $26.2 \pm 2.9 \%$ and $34.3 \pm 3.3 \%$ of the bacterial communities for A. hyacinthus and A. spathulata, respectively. At Rib reef, Betaproteobacteria made up only $4.54 \pm 1.1 \%$ and $18.6 \pm 2.02 \%$ of the communities for A. hyacinthus and A. spathulata, respectively.

Beta-diversity significantly varied according to reef, species and time point (Supplementary Table S3). Due to significant interactions, beta-diversity was also examined for each species at each reef where it significantly varied by time point; A. hyacinthus at Rib reef (PERMANOVA: $\mathrm{df}=4, F=3.97$, $p<0.01$ ), A. hyacinthus at Davies reef (PERMANOVA: df $=4, F=3.16, p<0.01), A$. spathulata at Rib reef (PERMANOVA: $\mathrm{df}=4, F=1.45, p<0.01$ ) and A. spathulata at Davies reef (PERMANOVA: $\mathrm{df}=4, F=2.83, p<0.01$ ). Pairwise PERMANOVA suggested no significant differences in the bacterial communities of $A$. hyacinthus among repeated sampling time points in February for Rib reef, but there were significant differences between the two February time points at Davies reef and between the October/November time points at both reefs (Supplementary Table S4). Pairwise PERMANOVA suggested no significant differences in bacterial communities of A. spathulata for all repeated sampling time points (February 2014 vs. February 2015 and October/November 2014 vs. October/November 2015) at Rib reef, but did show significant variations between repeated sampling points in February at Davies reef (Supplementary Table S5). For A. hyacinthus at both Rib and Davies reef the two February time points did not differ significantly, but the two October/November time points did (Supplementary Table S6). These data are supported by the CCA fitted time point vectors in nMDS, where data clouds from repeated sampling time points did not pull in the same direction, 


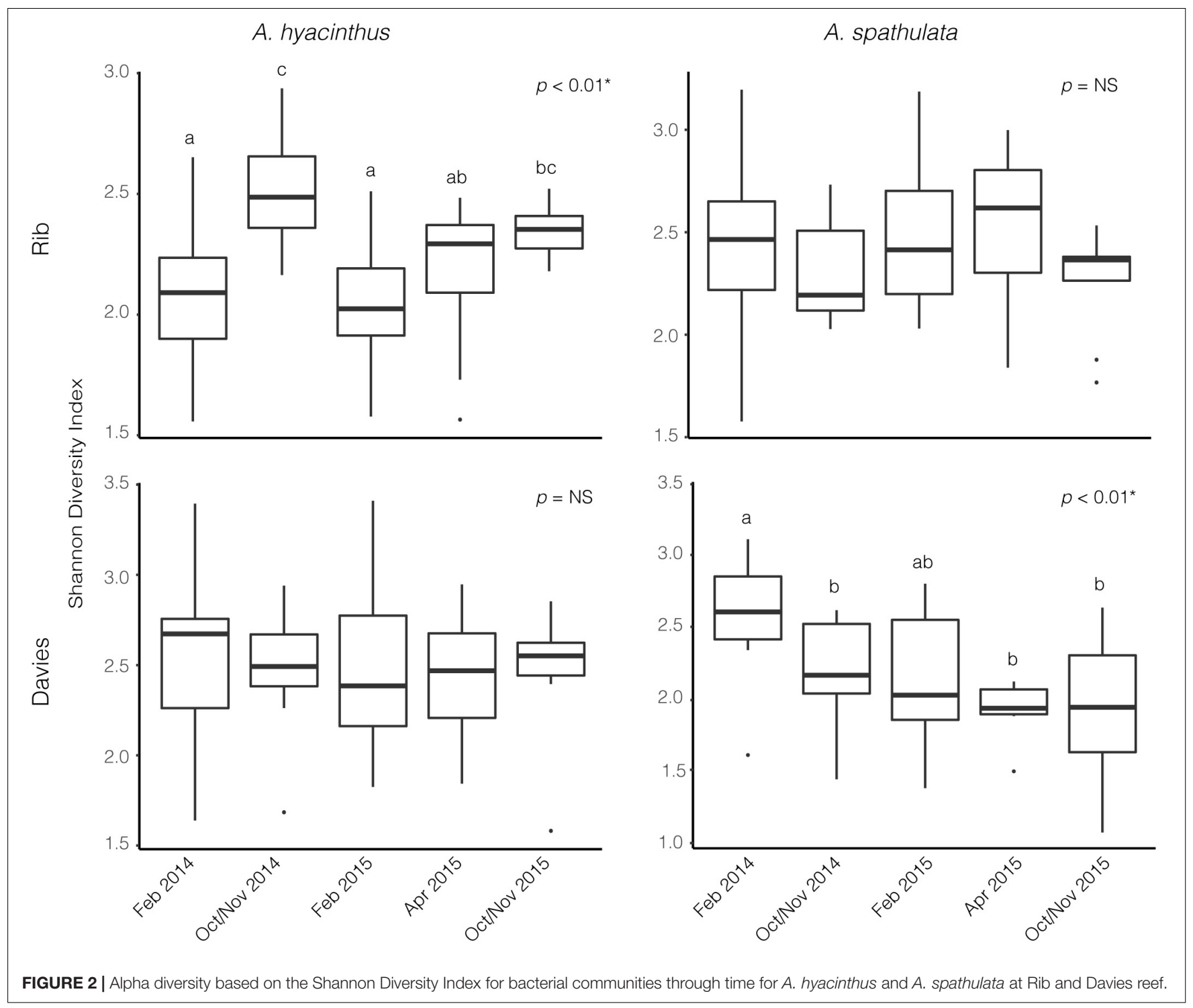

except for A. spathulata at Rib reef, where October/November 2014 and October/November 2015 both pulled in the same direction (Figure 4). According to CCA, time point represented a significant proportion $(p<0.05)$ of variation for both coral species and both reefs; 34 and $42 \%$ for A. hyacinthus at Rib and Davies reefs, respectively, and 14 and 39\% for A. spathulata at Rib and Davies reefs, respectively.

\section{Indicator Taxa for Repeated Sampling Time Points}

No significant bacterial indicator taxa were identified for A. hyacinthus at Rib reef for February, and neither coral species at either reef showed any significant bacterial indicators for October/November time points. Two indicator taxa of the February time points were recovered for A. hyacinthus at Davies reef: one Endozoicomonas ASV and one Pseudoalteromonas. Three indicator taxa of the February time points were identified for A. spathulata at Davies reef, including two Endozoicomonas ASVs, one of which was the same ASV as found in A. spathulata at Davies reef, and one Vibrio. One Endozoicomonas ASV, which was different from the others, was found as the single indicator taxon of the February time points for A. spathulata at Rib reef (see Supplementary Table S7).

\section{Symbiodiniaceae Community Characterization}

A total of 6,418,776 sequences from 215 samples corresponding to 54 unique Symbiodiniaceae sequence types were recovered to characterize the Symbiodiniaceae communities of both A. hyacinthus and A. spathulata at the two reefs and across the five time points. Alpha diversity of Symbiodiniaceae remained stable through time for A. hyacinthus and A. spathulata at Rib reef, but significantly varied for both species at Davies reef (ANOVA $_{\text {hyacinthus: }}$ : $\mathrm{df}=4, F=16.36, p<0.001$; $^{\text {ANOVA }}$ spathulata: 


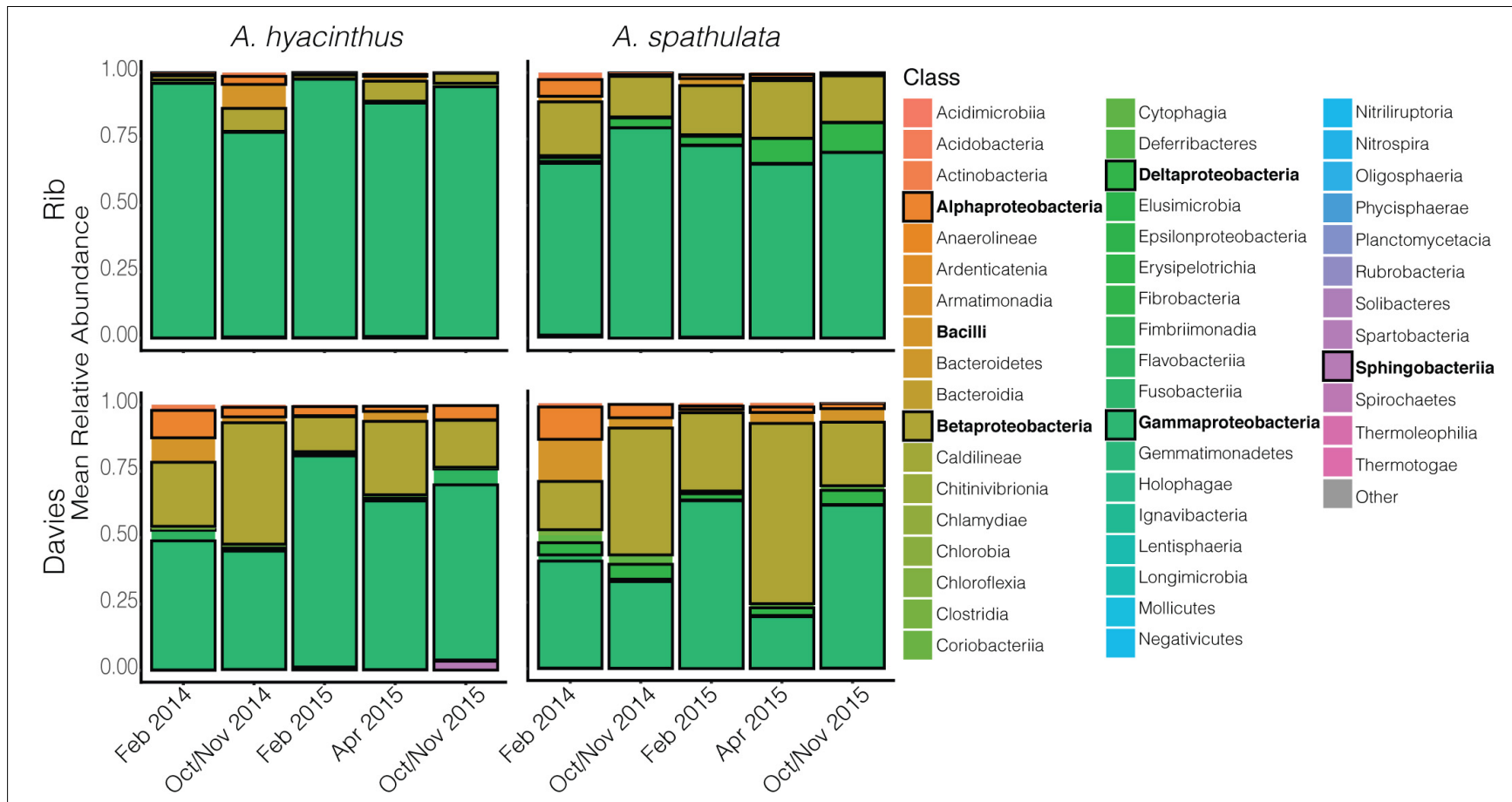

FIGURE 3 | Mean relative abundance of bacterial classes through time for both $A$. hyacinthus and $A$. spathulata at Rib and Davies reef. Classes in bold represent those that are in highest relative abundance.

$\mathrm{df}=4, F=4.07, p<0.01$; Figure 5). Observed species richness remained stable for $A$. hyacinthus and $A$. spathulata at both Rib and Davies reefs among time points.

Cladocopium C3k and Cspc sequence types were the dominant Symbiodiniaceae taxa through time for both species at both reefs (Figure 6 and Supplementary Figure S2) making up an average of $69.3 \pm 1.2 \%$ and $26.8 \pm 1.2 \%$ (mean \pm SEM), respectively, of the Symbiodiniaceae communities harbored by A. hyacinthus and A. spathulata. Beta-diversity also remained stable through time for A. hyacinthus at Rib and Davies Reef and for A. spathulata at Rib Reef. Beta-diversity of $A$. spathulata at Davies reef significantly varied among time points (PERMANOVA: $\mathrm{df}=4$, $F=4.86, p<0.01$; Supplementary Table S8), driven only by community differences between the two time points February 2015 and October/November 2015. Dominant taxa remained the same between these two time points, but the colonies had incorporated a low background abundance of the Cladocopium C1d type in February 2015, while in October/November 2015 these same colonies had replaced $\mathrm{C} 1 \mathrm{~d}$ with low background abundances of Cladocopium C3 types, including C3.10 and C3.12.

\section{Co-occurrences of Bacterial and Symbiodiniaceae Taxa}

The co-occurrences and correlation strengths of bacterial and Symbiodiniaceae taxa differed among time points within species and reef (Supplementary Figure S3). Among time points, Symbiodiniaceae correlated both positively and negatively with a number of bacterial taxa, including Endozoicomonas, Burkholderia-Paraburkholderia, Sphingomonas, and others.
However, only a small number of taxa had significant correlations $(>0.6$ or $<-0.6, p<0.05)$ when all time points were considered together for each species at each reef (Figures 7, 8). Symbiodiniaceae significantly correlated only with other Symbiodiniaceae, where the two dominant types, Cladocopium C3k and Cspc were negatively correlated with each other for both coral species at each reef. Most significant bacterial correlations occurred between ASVs of the same genus, for instance Endozoicomonas with Endozoicomonas and Burkholderia-Paraburkholderia with Burkholderia-Paraburkholderia. Some Endozoicomonas ASVs correlated positively with each other, while others correlated negatively.

\section{DISCUSSION}

\section{Microbial Communities Were Temporally Variable, but Do Not Exhibit a Seasonal Pattern}

The bacterial communities of both $A$. hyacinthus and A. spathulata were dominated by Proteobacteria, including the classes Gammaproteobacteria, Betaproteobacteria and Alphaproteobacteria, a pattern commonly observed in Acropora species (e.g., Ceh et al., 2011; Littman et al., 2011; Meron et al., 2011; Ziegler et al., 2017). The overall community composition was similar between $A$. hyacinthus and A. spathulata at the two reefs with little difference among colonies (i.e., genotype; Glasl et al., 2019), but there were consistent differences in 


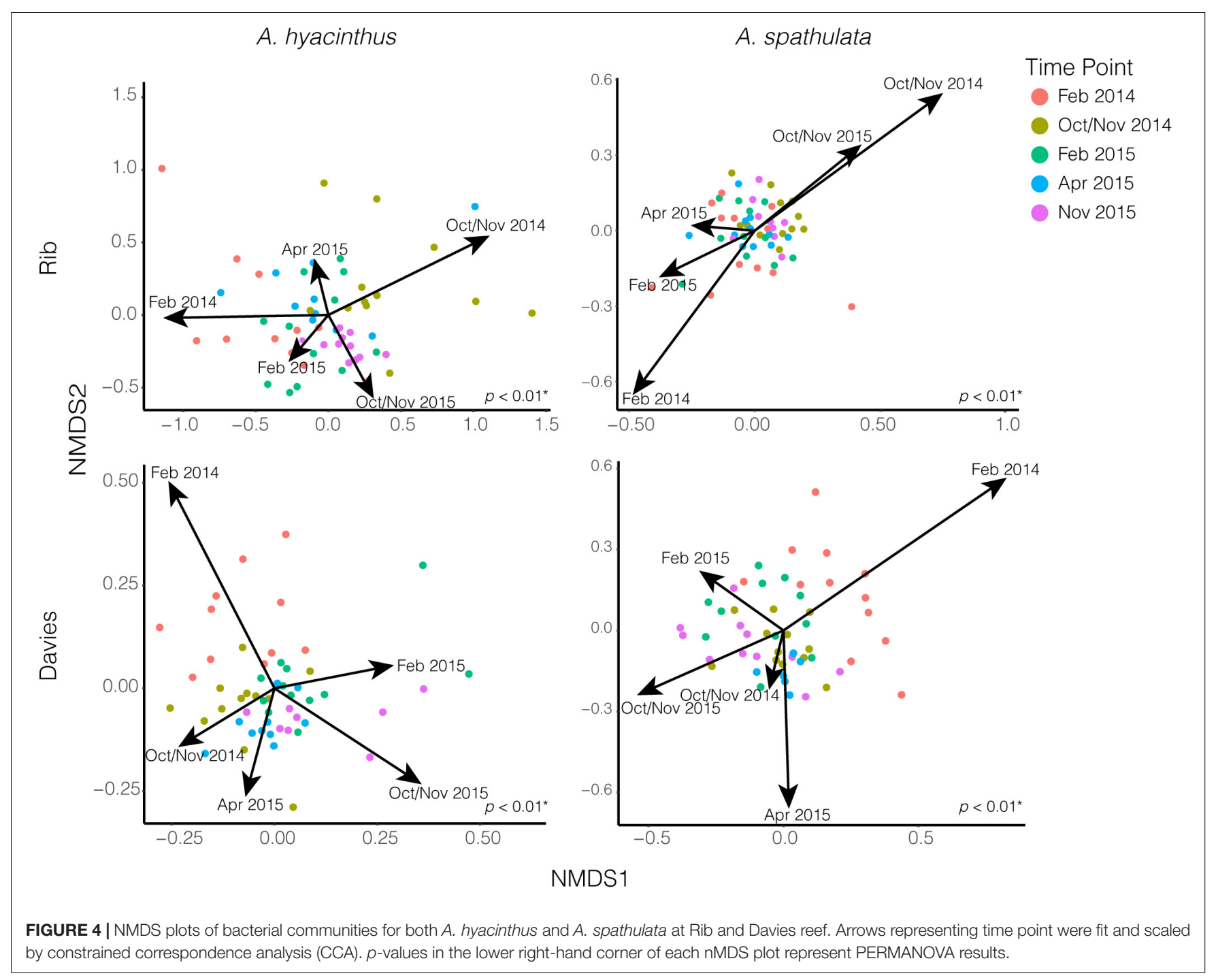

the relative abundance of certain taxa such as the Gammaand Betaproteobacteria according to reef. Coral bacterial communities have previously been found to have strong location or geographic signatures (e.g., Littman et al., 2009; Leite et al., 2018), and it has been proposed that the coral microbiome includes a site or location-specific component (HernandezAgreda et al., 2016). Rib and Davies reef are mid-shelf reefs on the GBR, both influenced by oceanic inflow (Brinkman et al., 2002). However, they are located approximately $150 \mathrm{~km}$ apart and could have different environmental influences, including differences in hydrodynamic flow, upwelling from offshore and land-based influences, such as nutrient levels as a result of run-off (e.g., Davies reef is much closer to the mouth of the Burdekin River than Rib reef, which can have extensive flood plumes; Wolanski and Van Senden, 1983). This may result in more variability in the environmental pool of microbes.

While there were significant variations in bacterial communities through time, there was little evidence of seasonal patterns within species and across reefs. Previous studies on the coral microbiome have also identified significant differences in the bacterial community composition through time (e.g., Ceh et al., 2011; Kimes et al., 2013; Li et al., 2014; Sharp et al., 2017; Cai et al., 2018). These studies were completed within a 1-year time period, yet suggested the observed changes were seasonal. The pattern from the present study instead supports the findings by Yang et al. (2017), where S. pistillata also exhibited highly dynamic temporal variations in its bacterial community composition, but with little evidence of seasonal cycles over a 2-year period. Therefore, the variations in bacterial communities among time points are likely influenced by factors other than season. This reinforces the conclusions made by Yang et al. (2017), who recommend that studies with a duration longer than 1 year are essential for understanding the drivers of temporal change in bacterial communities. Perhaps studies that exceed even 2 years are necessary to find consistent cyclical patterns due to inter-annual variation in environmental parameters 


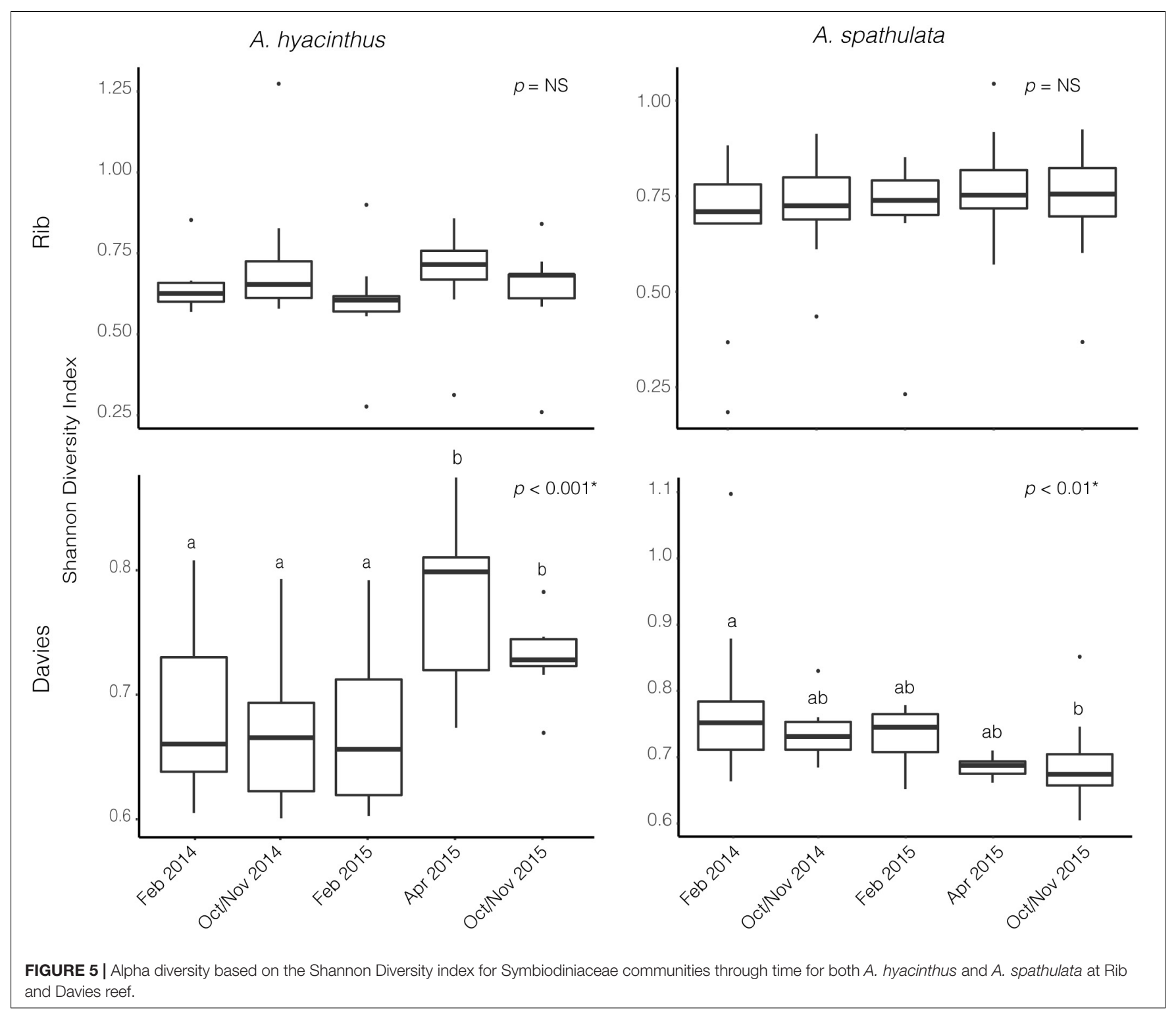

and to identify potential ontogenetic microbial shifts (e.g., Williams et al., 2015).

The dominant Symbiodiniaceae sequence types in A. hyacinthus and A. spathulata included both Cladocopium C3k and Cladocopium Cspc. Cladocopium C3 has been identified as a common symbiont of acroporids from central and southern GBR reefs (e.g., LaJeunesse et al., 2003, 2004b). In the present study, Cladocopium Cspc co-dominated, but was negatively correlated with $\mathrm{C} 3 \mathrm{k}$, perhaps representing a competitive interaction between the two dominant strains. However, these dominant strains were maintained throughout the 2-year sampling period, suggesting overall community structure was stable and did not reflect seasonal variation. Seasonal variation in the dominant Symbiodiniaceae types has been previously identified for some coral species (e.g., Chen et al., 2005; Ulstrup et al., 2008). In cases of temporally stable Symbiodiniaceae community composition (e.g.,
LaJeunesse et al., 2005; Thornhill et al., 2006a,b; Klepac et al., 2015; Cai et al., 2018), other seasonal variations are often present such as changes to cell density, pigment content, or photosynthetic efficiency (Fitt et al., 2000; Warner et al., 2002; Ulstrup et al., 2008). Seasonal variation in overall community composition was not evident in the data presented here, and smaller changes among time points were driven by background types, particularly at Davies reef, where alpha diversity of both $A$. hyacinthus and $A$. spathulata, and beta-diversity of $A$. spathulata varied significantly. Spatially, the population structure of Cladocopium spp. symbionts can be more complex than their hosts, showing divergence among closely located reefs (Davies et al., 2019), and suggesting there may have been different environmental pools of Cladocopium-type symbionts at the two reefs that were available for corals to uptake. Further, A. spathulata at Davies reef showed the acquisition of novel background 


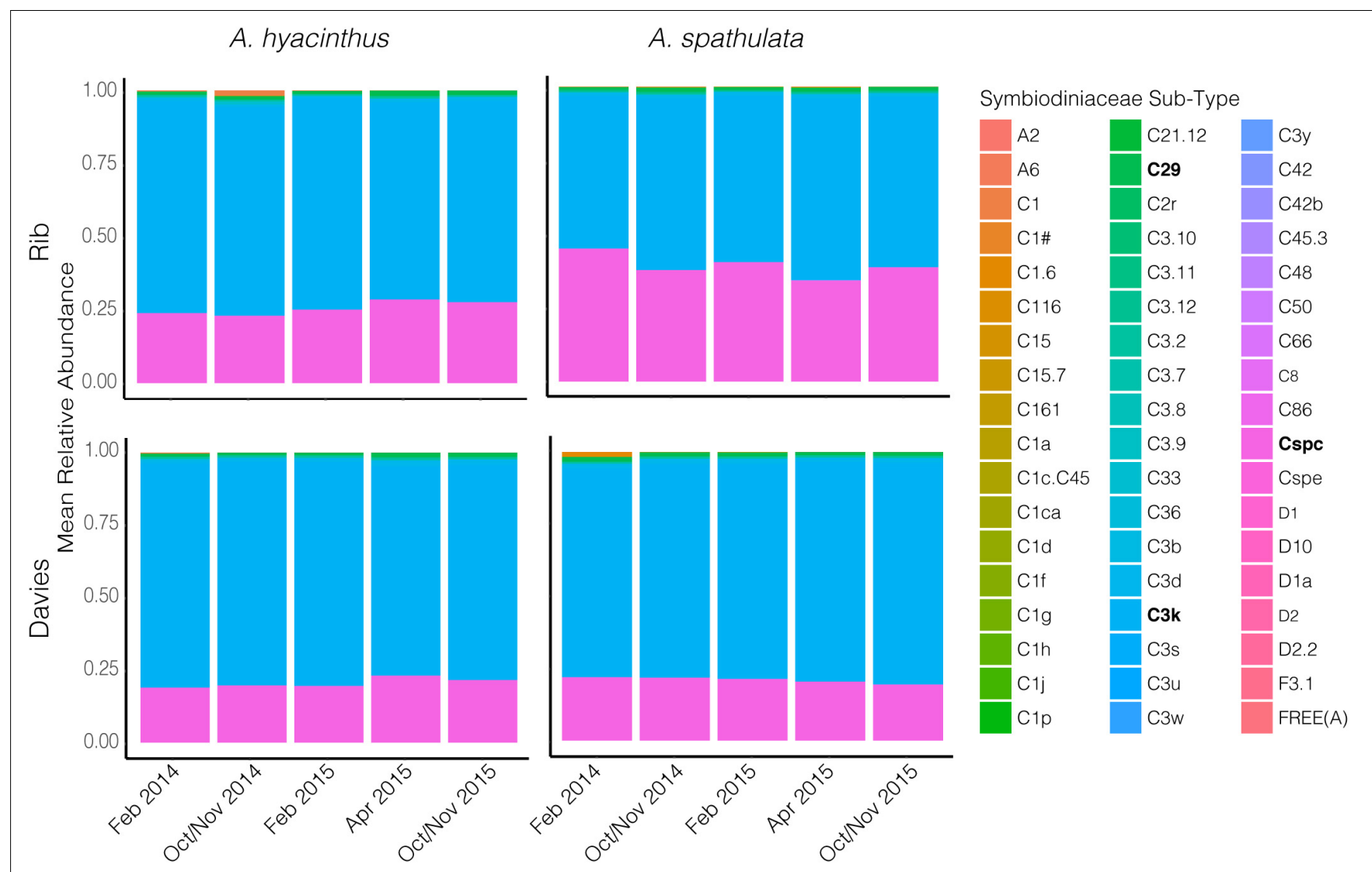

FIGURE 6 | Mean relative abundance of Symbiodiniaceae sequence sub-types through time for both $A$. hyacinthus and $A$. spathulata at Rib and Davies reef.

algal strains among time points. This symbiont switching in the rare biosphere has been found previously, but until recently, only following considerable bleaching events (Lewis and Coffroth, 2004; Boulotte et al., 2016) that did not occur even during peak summer temperatures during the present study. In the present study, switching was species-specific, suggesting some level of host regulation and supporting the idea of a host-specific "Symbiodiniaceae signature," as outlined in Rouzé et al. (2019).

Correlation and network analyses are often used to examine interactions between members of the coral holobiont. However, the majority of network studies in corals have so far looked at a single taxonomic group (e.g., bacteria: reviewed in Sweet and Bulling, 2017 or Symbiodiniaceae: Ziegler et al., 2018), while only a few have examined multiple groups (e.g., phage-bacteria: Soffer et al., 2015 or Symbiodiniaceaebacteria: Bernasconi et al., 2018; Bonthond et al., 2018). In the present study, the small number of significant correlations found between microbial taxa for each coral species at each reef suggests that there were few co-occurrences or mutual exclusions (e.g., negative interactions) that were either persistent through time or following seasonal patterns. When time points were pooled, Symbiodiniaceae had no significant correlations with any bacterial taxa. When time points were analyzed separately, the bacterial communities had higher numbers of significant correlations, which resulted in complex networks, while Symbiodiniaceae were interconnected with both other Symbiodiniaceae and a small number of bacterial taxa. These networks, however, were not consistent through time, and did not display any obvious seasonal patterns of microbial interactions. Previous studies have found Symbiodiniaceae correlating only with other Symbiodiniaceae (e.g., Bonthond et al., 2018), while others have found some connectivity with bacterial taxa (e.g., Bernasconi et al., 2018). However, the low number of studies incorporating network analyses for both the Symbiodiniaceae and bacterial components of the coral microbiome currently limits the ability to assess common patterns. Additionally, more useful networks may be created in future studies with the incorporation of bacterial/algal functional or metabolic data rather than simply taxonomic identity (e.g., Zhou et al., 2010; Steinway et al., 2015).

The results from this study suggest that both the composition of bacteria and Symbiodiniaceae communities and the interactions among microbial taxa are dynamic through time; few interactions remained consistent among all time points in each species at each reef. Future microbial functional analyses will be necessary for understanding this variability, along with a better understanding of the regulation of microbial symbioses by the coral host. Our results suggest that caution should be taken 


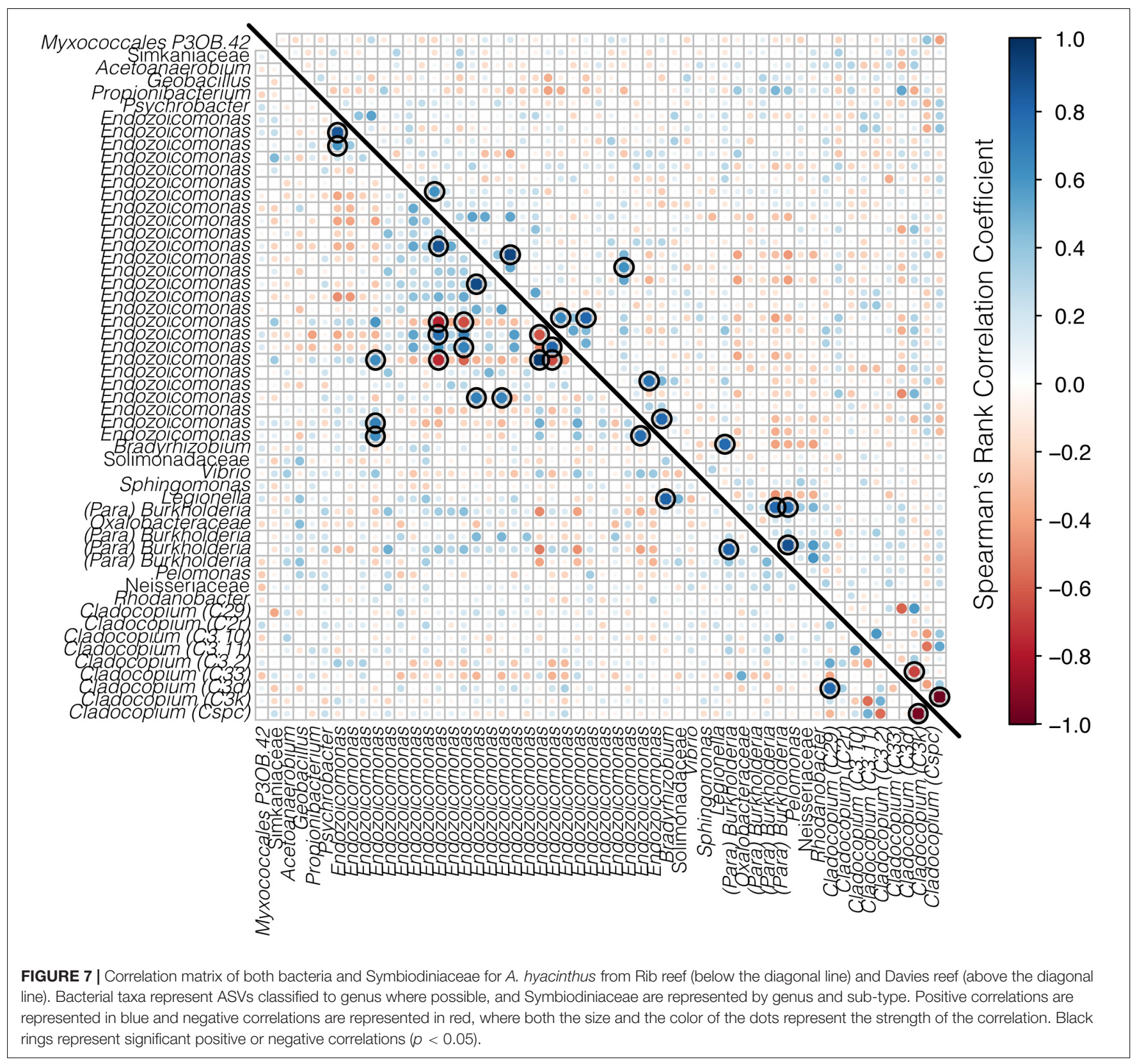

when making conclusions from a network or correlation analysis that represents only a single time point.

\section{Potential for Functional Differentiation in Endozoicomonas}

The present study found no bacterial indicator species that were significantly associated with the November time points across coral species. However, a small number of indicator taxa were consistently associated with both February time points for the two coral species, mostly consisting of Endozoicomonas strains. Endozoicomonas is a common bacterial genus that associates with a wide range of coral species, including those from the families Acroporidae (Ziegler et al., 2016, 2017),
Pocilloporidae (Bayer et al., 2013; Neave et al., 2017a; van Oppen et al., 2018), Fungiidae (Roder et al., 2015), and Poritidae (Apprill et al., 2016). This genus has been suggested to play a number of functional roles linked with coral health, such as carbohydrate cycling and protein transport (Neave et al., 2016), dimethylsufiopropionate (DMSP) degradation (Bourne et al., 2013), provision of amino acids (Neave et al., 2016), and, importantly, thermal or bleaching protection (Pantos et al., 2015). The presence of an Endozoicomonas ASV as an indicator of the February time points may suggest this strain provides some benefits during warm summer temperatures.

The two coral species in the present study shared one Endozoicomonas ASV as an indicator, but were also populated with other Endozoicomonas ASVs that were not 


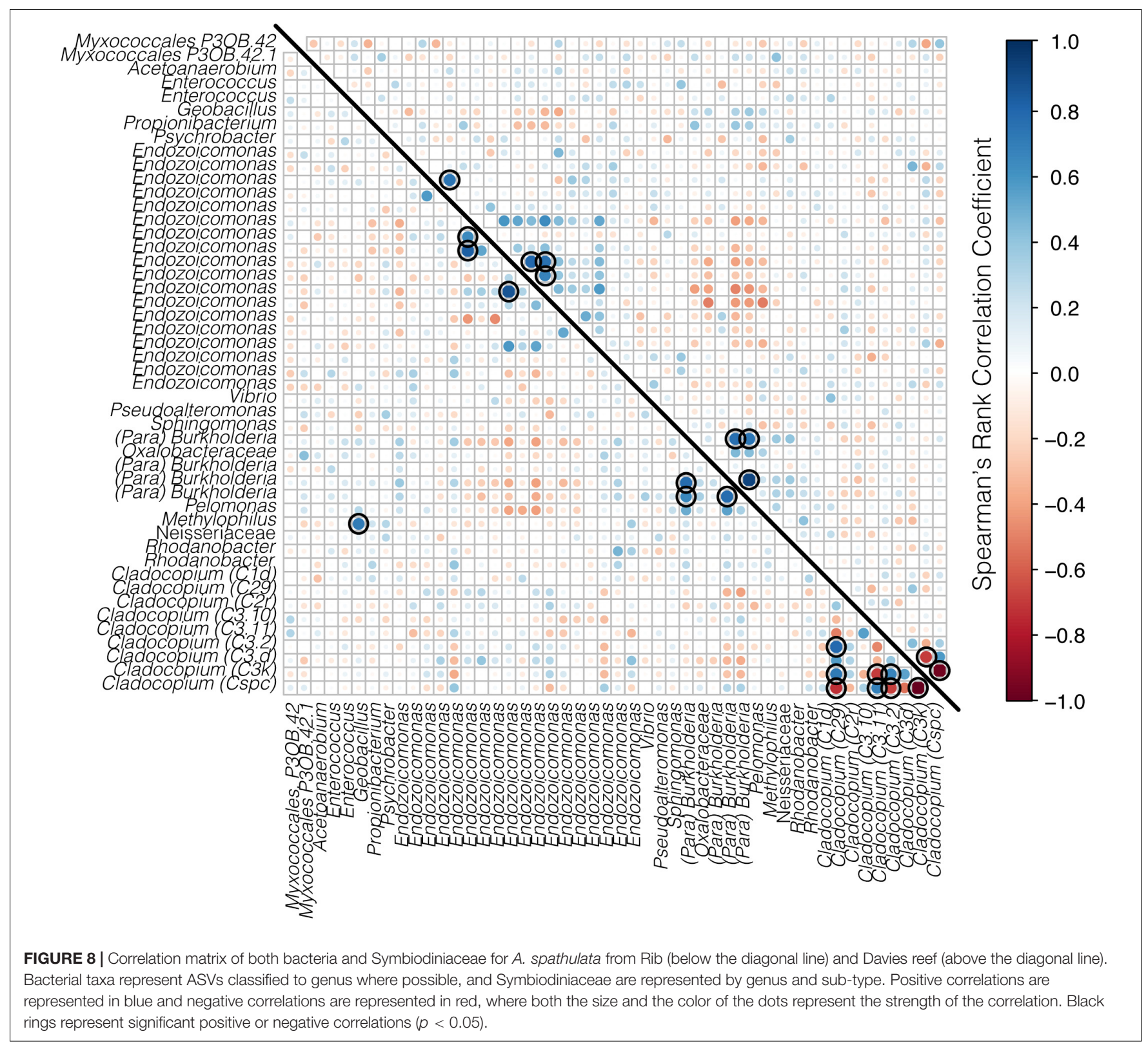

shared. This suggests some functional specificity among Endozoicomonas strains in relation to host species. Thus, while seasonal variation in overall community composition (i.e., taxonomy) was not observed, small differences in the relative abundance or presence/absence of closely related bacterial strains were observed, which may have consequences for the functional potential of these bacterial communities (e.g., Neave et al., 2017a). Interestingly, both the correlation and network analyses found that different Endozoicomonas strains correlated both positively and negatively with each other. While the correlation between different Endozoicomonas strains could be a result of intragenomic variation (Endozoicomonas genomes have been found to host more than one copy of the $16 \mathrm{~S}$ rRNA gene depending on species; Neave et al., 2014), it may also imply functional differentiation among Endozoicomonas sequence variants (Neave et al., 2017b). This highlights the importance of examining higher resolution taxonomic classification (e.g., ASVs) in metabarcoding studies, and future studies should incorporate functional analyses.

\section{Conclusion}

The microbiomes of $A$. hyacinthus and $A$. spathulata were complex and dynamic through time and variable according to reef and host species, yet not reflective of seasonality. This validates the findings of Yang et al. (2017) and reinforces their conclusion that longterm microbial surveys are essential for understanding the variable nature of the coral microbiome through time. Further studies are necessary to determine the 
consistency of these findings across greater time frames, spatial scales and coral taxa.

\section{DATA AVAILABILITY}

The datasets generated for this study can be found in NCBI Sequence Read Archive, accession number: PRJNA491379.

\section{ETHICS STATEMENT}

Anthozoans are not subject to ethics approval. Sampling for this study was carried out under the Great Barrier Reef Marine Park Authority and the Queensland Parks and Wildlife Service permit number G12/35236.1.

\section{AUTHOR CONTRIBUTIONS}

HE, HS, GT, and MO developed the research question. VM and NC were responsible for the original sampling design and both funding for and provision of the coral samples. HE performed the genetic laboratory work, bioinformatics, and analyses with statistical assistance from HS. HE was responsible for the initial draft of the manuscript, with editorial support from all co-authors.

\section{REFERENCES}

Ainsworth, T., Krause, L., Bridge, T., Torda, G., Raina, J. B., Zakrzewski, M., et al. (2015). The coral core microbiome identifies rare bacterial taxa as ubiquitous endosymbionts. ISME J. 9, 2261-2274. doi: 10.1038/ismej.2015.39

Andersson, A. F., Lindberg, M., Jakobsson, H., Bäckhed, F., Nyrén, P., and Engstrand, L. (2008). Comparative analysis of human gut microbiota by barcoded pyrosequencing. PLoS One 3:e2836. doi: 10.1371/journal.pone. 0002836

Apprill, A., Weber, L. G., and Santoro, A. E. (2016). Distinguishing between microbial habitats unravels ecological complexity in coral microbiomes. mSystems 1:e00143-16.

Arif, C., Daniels, C., Bayer, T., Banguera-Hinestroza, E., Barbrook, A., Howe, C. J., et al. (2014). Assessing Symbiodinium diversity in scleractinian corals via nextgeneration sequencing-based genotyping of the ITS2 rDNA region. Mol. Ecol. 23, 4418-4433. doi: 10.1111/mec.12869

Bahr, K. D., Jokiel, P. L., and Rodgers, K. S. (2017). Seasonal and annual calcification rates of the Hawaiian reef coral, Montipora capitata, under present and future climate change scenarios. ICES J. Mar. Sci. 74, 1083-1091. doi: 10.1093/icesjms/fsw078

Baker, A. (2001). Reef corals bleach to survive change. Nature 411, 765-766. doi: $10.1038 / 35081151$

Bates, N. R., Amat, A., and Andersson, A. J. (2010). Feedbacks and responses of coral calcification on the Bermuda reef system to seasonal changes in biological processes and ocean acidification. Biogeosciences 7, 2509-2530. doi: 10.5194/ bg-7-2509-2010

Bayer, T., Arif, C., Ferrier-Pagès, C., Zoccola, D., Aranda, M., and Voolstra, C. R. (2013). Bacteria of the genus Endozoicomonas dominate the microbiome of the Mediterranean gorgonian coral Eunicella cavolini. Mar. Ecol. Prog. Ser. 479, 75-84. doi: 10.3354/meps10197

Berkelmans, R., and van Oppen, M. J. H. (2006). The role of zooxanthellae in the thermal tolerance of corals: a "nugget of hope" for coral reefs in an era of climate change. Proc. R. Soc. B Biol. Sci. 273, 2305-2312. doi: 10.1098/rspb.2006. 3567

\section{FUNDING}

Funding for this research was provided by Paul G. Allen Philanthropies, the Australian Institute of Marine Science (AIMS), and AIMS@JCU, the joint venture between James Cook University and AIMS. This research was conducted as part of HE's Ph.D. research and HE acknowledges receipt of an AIMS@JCU Postgraduate Scholarship. MO acknowledges the Australian Research Council Laureate Fellowship FL180100036.

\section{ACKNOWLEDGMENTS}

The research presented here was conducted under the Great Barrier Reef Marine Park Authority and the Queensland Parks and Wildlife Service permit number G12/35236.1. The authors would like to thank P. Menendez, K. Damjanovic, and A. Kerwin for statistical advice, and L. Bay for access to coral samples.

\section{SUPPLEMENTARY MATERIAL}

The Supplementary Material for this article can be found online at: https://www.frontiersin.org/articles/10.3389/fmicb. 2019.01775/full\#supplementary-material

Bernasconi, R., Stat, M., Koenders, A., and Huggett, M. J. (2018). Global networks of Symbiodinium-bacteria within the coral holobiont. Microb. Ecol. 77, 794-807. doi: 10.1007/s00248-018-1255-1254

Blackall, L. L., Wilson, B., and Van Oppen, M. J. H. (2015). Coral-the world's most diverse symbiotic ecosystem. Mol. Ecol. 24, 5330-5347. doi: 10.1111/mec.13400

Bolyen, E., Rideout, J. R., Dillon, M. R., Bokulich, N. A., Abnet, C., Al-Ghalith, G. A., et al. (2018). QIIME 2: reproducible, interactive, scalable, and extensible microbiome data science. Peerj Prepr. 6:e27295v2. doi: 10.7287/peerj.preprints. 27295v2

Bonthond, G., Merselis, D. G., Dougan, K. E., Graff, T., Todd, W., Fourqurean, J. W., et al. (2018). Inter-domain microbial diversity within the coral holobiont Siderastrea siderea from two depth habitats. PeerJ 6:e4323. doi: 10.7717/peerj. 4323

Boulotte, N. M., Dalton, S. J., Carroll, A. G., Harrison, P. L., Putnam, H. M., Peplow, L. M., et al. (2016). Exploring the Symbiodinium rare biosphere provides evidence for symbiont switching in reef-building corals. ISMJ J. 10, 2693-2701. doi: 10.1038/ismej.2016.54

Bourne, D. G., Dennis, P. G., Uthicke, S., Soo, R. M., Tyson, G. W., and Webster, N. (2013). Coral reef invertebrate microbiomes correlate with the presence of photosymbionts. ISME J. 7, 1452-1458. doi: 10.1038/ismej.2012.172

Bourne, D. G., Morrow, K. M., and Webster, N. S. (2016). Insights into the coral microbiome: underpinning the health and resilience of reef ecosystems. Annu. Rev. Microbiol. 70, 317-340. doi: 10.1146/annurev-micro-102215-095440

Bourne, D. G., and Webster, N. S. (2013). "Coral reef bacterial communities," in The Prokaryotes - Prokaryotic Communities and Ecophysiology, eds E. Rosenberg, E. F. Delong, S. Lory, E. Stackebrandt, and F. Thompson (Berlin: Springer Berlin Heidelberg), 163-187. doi: 10.1007/978-3-642-30123-0_48

Brinkman, R., Wolanski, E., Deleersnijder, E., McAllister, F., and Skirving, W. (2002). Oceanic inflow from the coral sea into the great barrier reef. Estuar. Coast. Shelf Sci. 54, 655-668. doi: 10.1006/ecss.2001.0850

Cai, L., Zhou, G., Tong, H., Tian, R., Zhang, W., Ding, W., et al. (2018). Season structures prokaryotic partners but not algal symbionts in subtropical hard corals. Appl. Microbiol. Biotechnol. 102, 4963-4973. doi: 10.1007/s00253-0188909-5 
Callahan, B. J., McMurdie, P. J., Rosen, M. J., Han, A. W., Johnson, A. J. A., and Holmes, S. P. (2016). DADA2: high-resolution sample inference from illumina amplicon data. Nat. Methods 13, 581-583. doi: 10.1038/nmeth.3869

Ceh, J., Van Keulen, M., and Bourne, D. G. (2011). Coral-associated bacterial communities on ningaloo reef, Western Australia. FEMS Microbiol. Ecol. 75, 134-144. doi: 10.1111/j.1574-6941.2010.00986.x

Chen, C. A., Wang, J. T., Fang, L. S., and Yang, Y. W. (2005). Fluctuating algal symbiont communities in Acropora palifera (Scleractinia: Acroporidae) from Taiwan. Mar. Ecol. Prog. Ser. 295, 113-121. doi: 10.3354/meps295113

Costa, O. S., Attrill, M. J., and Nimmo, M. (2006). Seasonal and spatial controls on the delivery of excess nutrients to nearshore and offshore coral reefs of Brazil. J. Mar. Syst. 60, 63-74. doi: 10.1016/j.jmarsys.2005.11.006

Csardi, G., and Nepusz, T. (2006). The igraph software package for complex network research. Int. J. Complex Syst. 1695, 1-9.

Damjanovic, K., Blackall, L. L., Webster, N. S., and van Oppen, M. J. H. (2017). The contribution of microbial biotechnology to mitigating coral reef degradation. Microb. Biotechnol. 10, 1236-1243. doi: 10.1111/1751-7915.12769

Davies, S. W., Wham, D., Kanke, M. R., and Matz, M. (2019). Contrasting population genetic structure in Acropora coral hosts and their algal symbionts across multiple spatial scales. bioRxiv

De Cáceres, M., and Legendre, P. (2009). Associations between species and groups of sites: indices and statistical inference. Ecology 90, 3566-3574. doi: 10.1890/ 08-1823.1

Fitt, W. K., Mcfarland, I. F. K., Warner, M. E., and Chilcoat, G. C. (2000). Seasonal patterns of tissue biomass and densities of symbiotic dinoflagellates in reef corals and relation to coral bleaching. Limnology 45, 677-685. doi: 10.4319/ lo.2000.45.3.0677

Fox, J., and Weisberg, S. (2011). An R companion to Applied Regression, 2nd Edn. Thousand Oaks,CA: SAGE Publications.

Garren, M., Raymundo, L., Guest, J., Harvell, C. D., and Azam, F. (2009). Resilience of coral-associated bacterial communities exposed to fish farm effluent. PLoS One 4:e7319. doi: 10.1371/journal.pone.0007319

Glasl, B., Smith, C. E., Bourne, D. G., and Webster, N. S. (2019). Disentangling the effect of host-genotype and environment on the microbiome of the coral Acropora tenuis. PeerJ 7:e6377. doi: 10.7717/peerj.6377

Graves, S., Piepho, H. P., Selzer, L., and Dorai-Raj, S. (2015). MultcompView: Visualizations of Paired Comparisons. Available at: https://cran.rproject.org/web/packages/multcompView/index.html (accessed June 12, 2018).

Hernandez-Agreda, A., Gates, R. D., and Ainsworth, T. D. (2017). Defining the core microbiome in corals' microbial soup. Trends Microbiol. 25, 125-140. doi: $10.1016 /$ j.tim.2016.11.003

Hernandez-Agreda, A., Leggat, W., Bongaerts, P., and Ainsworth, T. D. (2016). The microbial signature provides insight into the mechanistic basis of coral success across reef habitats. $m$ Bio $7,1-10$. doi: 10.1128/mBio.00560-16

Kimes, N. E., Johnson, W. R., Torralba, M., Nelson, K. E., Weil, E., and Morris, P. J. (2013). The Montastraea faveolata microbiome: ecological and temporal influences on a Caribbean reef-building coral in decline. Environ. Microbiol. 15, 2082-2094. doi: 10.1111/1462-2920.12130

Kimes, N. E., Van Nostrand, J. D., Weil, E., Zhou, J., and Morris, P. J. (2010). Microbial functional structure of Montastraea faveolata, an important Caribbean reef-building coral, differs between healthy and yellow-band diseased colonies. Environ. Microbiol. 12, 541-556. doi: 10.1111/j.1462-2920. 2009.02113.x

Klepac, C., Beal, J., Kenkel, C., Sproles, A., Polinski, J., Williams, M., et al. (2015). Seasonal stability of coral-Symbiodinium associations in the subtropical coral habitat of St. Lucie Reef, Florida. Mar. Ecol. Prog. Ser. 532, 137-151. doi: 10. 3354/meps11369

LaJeunesse, T. C., Bhagooli, R., Hidaka, M., DeVantier, L., Done, T., Schmidt, G. W., et al. (2004a). Closely related Symbiodinium spp. differ in relative dominance in coral reef host communities across environmental, latitudinal and biogeographic gradients. Mar. Ecol. Prog. Ser. 284, 147-161. doi: 10.3354/ meps 284147

LaJeunesse, T. C., Thornhill, D. J., Cox, E. F., Stanton, F. G., Fitt, W. K., and Schmidt, G. W. (2004b). High diversity and host specificity observed among symbiotic dinoflagellates in reef coral communities from Hawaii. Coral Reefs $23,596-603$.
LaJeunesse, T. C., Lee, S., Bush, S., and Bruno, J. F. (2005). Persistence of noncaribbean algal symbionts in Indo-Pacific mushroom corals released to Jamaica 35 years ago. Coral Reefs 24, 157-159. doi: 10.1007/s00338-004-0436-4

LaJeunesse, T. C., Loh, W. K. W., Van Woesik, R., Hoegh-Guldberg, O., Schmidt, G. W., and Fitt, W. K. (2003). Low symbiont diversity in southern great barrier reef corals, relative to those of the Caribbean. Limnol. Ocean. 48, 2046-2054. doi: 10.4319/lo.2003.48.5.2046

Lee, M. D., Walworth, N. G., Sylvan, J. B., Edwards, K. J., and Orcutt, B. N. (2015). Microbial communities on seafloor basalts at dorado outcrop reflect level of alteration and highlight global lithic clades. Front. Microbiol. 6:1470. doi: 10.3389/fmicb.2015.01470

Lee, O. O., Yang, J., Bougouffa, S., Wang, Y., Batang, Z., Tian, R., et al. (2012). Spatial and species variations in bacterial communities associated with corals from the Red sea as revealed by pyrosequencing. Appl. Environ. Microbiol. 78, 7173-7184. doi: 10.1128/aem.01111-12

Leite, D. C. A., Salles, J. F., Calderon, E. N., Castro, C. B., Bianchini, A., Marques, J. A., et al. (2018). Coral bacterial-core abundance and network complexity as proxies for anthropogenic pollution. Front. Microbiol. 9:833. doi: 10.3389/ fmicb.2018.00833

Lenth, R. V. (2016). Least-squares means: the R package lsmeans. J. Stat. Softw. 69 , 1-33. doi: 10.18637/jss.v069.i01

Lewis, C. L., and Coffroth, M. A. (2004). The acquisition of exogenous algal symbionts by an octocoral after bleaching. Science 304, 1490-1492. doi: 10.1126/ science. 1097323

Lewis, D. H., and Smith, D. C. (1971). The autotrophic nutrition of symbiotic marine coelenterates with special reference to hermatypic corals. I. Movement of photosynthetic products between the symbionts. Proc. R. Soc. B Biol. Sci. 178, 111-129. doi: 10.1098/rspb.1971.0055

Li, J., Chen, Q., Long, L. J., Dong, J., De, Yang, J., and Zhang, S. (2014). Bacterial dynamics within the mucus, tissue and skeleton of the coral Porites lutea during different seasons. Sci. Rep. 4, 1-8. doi: 10.1038/srep07320

Littman, R., Willis, B. L., and Bourne, D. G. (2011). Metagenomic analysis of the coral holobiont during a natural bleaching event on the great barrier reef. Environ. Microbiol. Rep. 3, 651-660. doi: 10.1111/j.1758-2229.2010.00234.x

Littman, R. A., Willis, B. L., Pfeffer, C., and Bourne, D. G. (2009). Diversities of coral-associated bacteria differ with location, but not species, for three acroporid corals on the great barrier reef. FEMS Microbiol. Ecol. 68, 152-163. doi: 10.1111/j.1574-6941.2009.00666.x

McMurdie, P. J., and Holmes, S. (2013). phyloseq: an R package for reproducible interactive analysis and graphics of microbiome census data. PLoS One 8:e61217. doi: 10.1371/journal.pone.0061217

Meron, D., Atias, E., Iasur Kruh, L., Elifantz, H., Minz, D., Fine, M., et al. (2011). The impact of reduced $\mathrm{pH}$ on the microbial community of the coral Acropora eurystoma. ISME J. 5, 51-60. doi: 10.1038/ismej.2010.102

Muscatine, L., and Porter, J. W. (1977). Reef corals: mutualistic symbioses adapted to nutrient-poor environments. Bioscience 27, 454-460. doi: 10.2307/1297526

Neave, M. J., Apprill, A., Ferrier-Pagès, C., and Voolstra, C. R. (2016). Diversity and function of prevalent symbiotic marine bacteria in the genus Endozoicomonas. Appl. Microbiol. Biotechnol. 100, 8315-8324. doi: 10.1007/s00253-016-7777-0

Neave, M. J., Michell, C. T., Apprill, A., and Voolstra, C. R. (2014). Whole-genome sequences of three symbiotic endozoicomonas strains. Genome Announc. 2:e00802-14. doi: 10.1128/genomeA.00802-14

Neave, M. J., Michell, C. T., Apprill, A., and Voolstra, C. R. (2017a). Endozoicomonas genomes reveal functional adaptation and plasticity in bacterial strains symbiotically associated with diverse marine hosts. Sci. Rep. 7:40579. doi: 10.1038/srep40579

Neave, M. J., Rachmawati, R., Xun, L., Michell, C. T., Bourne, D. G., Apprill, A., et al. (2017b). Differential specificity between closely related corals and abundant Endozoicomonas endosymbionts across global scales. ISME J. 11, 186-200. doi: 10.1038/ismej.2016.95

O’Brien, P. A., Smith, H. A., Fallon, S., Fabricius, K., Willis, B. L., Morrow, K. M., et al. (2018). Elevated CO2 has little influence on the bacterial communities associated with the $\mathrm{pH}$-tolerant coral, massive Porites spp. Front. Microbiol. 9:2621. doi: 10.3389/fmicb.2018.02621

Oksanen, J., Blanchet, G., Friendly, M., Kindt, R., Legendre, P., McGlinn, D., et al. (2018). Vegan: Community Ecology Package. Available at: https://cran.r-project. org, https://github.com/vegandevs/vegan (accessed June 2, 2018). 
Pantos, O., Bongaerts, P., Dennis, P. G., Tyson, G. W., and Hoegh-Guldberg, O. (2015). Habitat-specific environmental conditions primarily control the microbiomes of the coral Seriatopora hystrix. ISME J. 9, 1916-1927. doi: 10. 1038/ismej.2015.3

Peixoto, R. S., Rosado, P. M., Leite, D. C., Rosado, A. S., and Bourne, D. G. (2017). Beneficial microorganisms for corals (BMC): proposed mechanisms for coral health and resilience. Front. Microbiol. 8:341. doi: 10.3389/fmicb.2017.00341

Pinheiro, J., Bates, D., DebRoy, S., Sarkar, D., and R Core Team (2018). Nlme: Linear and Nonlinear Mixed Effects Models. Available at: https:/CRAN.Rproject.org/package=nlme (accessed June 2, 2018).

Pochon, X., Putnam, H. M., Burki, F., and Gates, R. D. (2012). Identifying and characterizing alternative molecular markers for the symbiotic and free-living dinoflagellate genus Symbiodinium. PLoS One 7:e29816. doi: 10.1371/journal. pone.0029816

Quast, C., Pruesse, E., Yilmaz, P., Gerken, J., Schweer, T., Yarza, P., et al. (2013). The SILVA ribosomal RNA gene database project: improved data processing and web-based tools. Nucleic Acids Res. 41, 590-596. doi: 10.1093/nar/ gks1219

R Core Team (2018). R: A Language and Environmental for Statistical Computing. Vienna: R Foundation for Statistical Computing.

Raina, J. B., Tapiolas, D., Willis, B. L., and Bourne, D. G. (2009). Coral-associated bacteria and their role in the biogeochemical cycling of sulfur. Appl. Environ. Microbiol. 75, 3492-3501. doi: 10.1128/AEM.02567-08

Reshef, L., Koren, O., Loya, Y., Zilber-Rosenberg, I., and Rosenberg, E. (2006). The coral probiotic hypothesis. Environ. Microbiol. 8, 2068-2073. doi: 10.1111/ j.1462-2920.2006.01148.x

Ritchie, K. B. (2006). Regulation of microbial population by coral surface mucus and mucus-associated bacteria. Mar. Ecol. Prog. Ser. 322, 1-14. doi: 10.3354/ meps322001

Roder, C., Bayer, T., Aranda, M., Kruse, M., and Voolstra, C. R. (2015). Microbiome structure of the fungid coral Ctenactis echinata aligns with environmental differences. Mol. Ecol. 24, 3501-3511. doi: 10.1111/mec.13251

Rognes, T., Flouri, T., Nichols, B., Quince, C., and Mahé, F. (2016). VSEARCH: a versatile open source tool for metagenomics. PeerJ 4:e2584. doi: 10.7717/peerj. 2584

Rohwer, F., and Kelley, S. T. (2004). "Culture-independent analyses of coralassociated microbes," in Coral Health and Disease, eds E. Rosenberg and Y. Loya (Berlin: Springer Berlin Heidelberg), 265-277. doi: 10.1007/978-3-662-06414$6 \_14$

Rouzé, H., Lecellier, G. J., Pochon, X., Torda, G., and Berteaux-Lecellier, V. (2019). Unique Symbiodiniaceae clade signature of coral colonies revealed through spatio-temporal survey of three coral species in Moorea (French Polynesia). Sci. Rep. 9:7921.

Shannon, P., Markiel, A., Ozier, O., Baliga, N. S., Wang, J. T., Ramage, D., et al. (2003). Cytoscape: a software environment for integrated models of biomolecular interaction networks. Genome Res. 13, 2498-2504. doi: 10.1101/ gr.1239303

Sharp, K. H., Pratte, Z. A., Kerwin, A. H., Rotjan, R. D., and Stewart, F. J. (2017). Season, but not symbiont state, drives microbiome structure in the temperate coral Astrangia poculata. Microbiome 5:120.

Soffer, N., Zaneveld, J., and Vega Thurber, R. (2015). Phage-bacteria network analysis and its implication for the understanding of coral disease. Environ. Microbiol. 17, 1203-1218. doi: 10.1111/1462-2920.12553

Steinway, S. N., Biggs, M. B., Loughran, T. P., Papin, J. A., and Albert, R. (2015). Inference of network dynamics and metabolic interactions in the gut microbiome. PLoS Comput. Biol. 11:e1004338. doi: 10.1371/journal.pcbi. 1004338

Sweet, M. J., Brown, B. E., Dunne, R. P., Singleton, I., and Bulling, M. (2017). Evidence for rapid, tide-related shifts in the microbiome of the coral Coelastrea aspera. Coral Reefs 36, 815-828. doi: 10.1007/s00338-017-1572-y

Sweet, M. J., and Bulling, M. T. (2017). On the importance of the microbiome and pathobiome in coral health and disease. Front. Mar. Sci. 4:9. doi: 10.3389/fmars. 2017.00009

Thompson, J. R., Rivera, H. E., Closek, C. J., and Medina, M. (2015). Microbes in the coral holobiont: partners through evolution, development, and ecological interactions. Front. Cell. Infect. Microbiol. 4:176. doi: 10.3389/fcimb.2014. 00176
Thornhill, D. J., Fitt, W. K., and Schmidt, G. W. (2006a). Highly stable symbioses among western Atlantic brooding corals. Coral Reefs 25, 515-519. doi: 10.1007/ s00338-006-0157-y

Thornhill, D. J., LaJeunesse, T. C., Kemp, D. W., Fitt, W. K., and Schmidt, G. W. (2006b). Multi-year, seasonal genotypic surveys of coral-algal symbioses reveal prevalent stability or post-bleaching reversion. Mar. Biol. 148, 711-722. doi: 10.1007/s00227-005-0114-2

Torda, G., Donelson, J. M., Aranda, M., Barshis, D. J., Bay, L., Berumen, M. L., et al. (2017). Rapid adaptive responses to climate change in corals. Nat. Clim. Chang. 7, 627-636. doi: 10.1038/nclimate3374

Ulstrup, K. E., Hill, R., Van Oppen, M. J. H., Larkum, A. W. D., and Ralph, P. J. (2008). Seasonal variation in the photo-physiology of homogeneous and heterogeneous Symbiodinium consortia in two scleractinian corals. Mar. Ecol. Prog. Ser. 361, 139-150. doi: 10.3354/meps07360

van Oppen, M., Gates, R., Blackall, L., Cantin, N., Chakravarti, L., Chan, W., et al. (2017). Shifting paradigms in restoration of the world's coral reefs. Glob. Chang. Biol. 23, 3437-3448. doi: 10.1111/gcb.13647

van Oppen, M. J. H., Bongaerts, P., Frade, P., Peplow, L. M., Boyd, S. E., Nim, H. T., et al. (2018). Adaptation to reef habitats through selection on the coral animal and its associated microbiome. Mol. Ecol. 27, 2956-2971. doi: 10.1111/ mec. 14763

van Oppen, M. J. H., Oliver, J. K., Putnam, H. M., and Gates, R. D. (2015). Building coral reef resilience through assisted evolution. Proc. Natl. Acad. Sci. U.S.A. 112, 2307-2313. doi: 10.1073/pnas.1422301112

Warner, M. E., Chilcoat, G. C., McFarland, F. K., and Fitt, W. K. (2002). Seasonal fluctuations in the photosynthetic capacity of photosystem II in symbiotic dinoflagellates in the Caribbean reef-building coral Montastraea. Mar. Biol. 141, 31-38. doi: 10.1007/s00227-0020807-8

Wei, T., and Simko, V. (2017). R Package "Corrplot": Visualization of a Correlation Matrix. Available at: https://github.com/taiyun/corrplot (accessed June 27, 2018).

Wickham, H. (2009). Ggplot2: Elegant Graphics for Data Analysis. Available at: http://ggplot2.tidyverse.org (accessed June 5, 2018).

Williams, A. D., Brown, B. E., Putchim, L., and Sweet, M. J. (2015). Age-related shifts in bacterial diversity in a reef coral. PLoS One 10:e0144902. doi: 10.1371/ journal.pone.0144902

Wolanski, E., and Van Senden, D. (1983). Mixing of burdekin river flood waters in the great barrier reef. Mar. Freshw. Res. 34, 49-63. doi: 10.1071/MF98 30049

Yang, S. H., Tseng, C. H., Huang, C. R., Chen, C. P., Tandon, K., Lee, S. T. M., et al. (2017). Long-term survey is necessary to reveal various shifts of microbial composition in corals. Front. Microbiol. 8:1094. doi: 10.3389/fmicb.2017.01094

Zhou, J., Deng, Y., Luo, F., He, Z., Tu, Q., and Zhi, X. (2010). Functional molecular ecological networks. mBio $1,1-10$.

Ziegler, M., Eguíluz, V. M., Duarte, C. M., and Voolstra, C. R. (2018). Rare symbionts may contribute to the resilience of coral-algal assemblages. ISME J. 12, 161-172. doi: 10.1038/ismej.2017.151

Ziegler, M., Roik, A., Porter, A., Zubier, K., Mudarris, M. S., Ormond, R., et al. (2016). Coral microbial community dynamics in response to anthropogenic impacts near a major city in the central Red sea. Mar. Pollut. Bull. 105, 629-640. doi: 10.1016/j.marpolbul.2015.12.045

Ziegler, M., Seneca, F. O., Yum, L. K., Palumbi, S. R., and Voolstra, C. R. (2017). Bacterial community dynamics are linked to patterns of coral heat tolerance. Nat. Commun. 8, 1-8. doi: 10.1038/ncomms14213

Conflict of Interest Statement: The authors declare that the research was conducted in the absence of any commercial or financial relationships that could be construed as a potential conflict of interest.

Copyright (C) 2019 Epstein, Smith, Cantin, Mocellin, Torda and van Oppen. This is an open-access article distributed under the terms of the Creative Commons Attribution License (CC BY). The use, distribution or reproduction in other forums is permitted, provided the original author(s) and the copyright owner(s) are credited and that the original publication in this journal is cited, in accordance with accepted academic practice. No use, distribution or reproduction is permitted which does not comply with these terms. 